\title{
Jan Keupp, Romedio Schmitz-Esser (dir.), Neue alte Sachlichkeit. Studienbuch Materialität des Mittelalters
}

Jean-Dominique Delle Luche

\section{OpenEdition}

Édition électronique

URL : http://journals.openedition.org/ifha/9052

DOI : $10.4000 /$ ifha. 9052

ISSN : 2198-8943

\section{Éditeur}

IFRA - Institut franco-allemand (sciences historiques et sociales)

\section{Référence électronique}

Jean-Dominique Delle Luche, « Jan Keupp, Romedio Schmitz-Esser (dir.), Neue alte Sachlichkeit. Studienbuch Materialität des Mittelalters », Revue de I'IFHA [En ligne], Date de recension, mis en ligne le 14 juin 2018, consulté le 24 septembre 2020. URL : http://journals.openedition.org/ifha/9052 ; DOI : https://doi.org/10.4000/ifha.9052

Ce document a été généré automatiquement le 24 septembre 2020.

(CIFHA 


\section{Jan Keupp, Romedio Schmitz-Esser (dir.), Neue alte Sachlichkeit. Studienbuch Materialität des Mittelalters}

Jean-Dominique Delle Luche

\section{RÉFÉRENCE}

Jan Keupp, Romedio Schmitz-Esser (dir.), Neue alte Sachlichkeit. Studienbuch Materialität des Mittelalters, Ostfildern: Thorbecke, 2015, 375 p., $39 €$ 
Le «tournant matériel », ou plutôt le regain récent de la matérialité auprès de la recherche francophone et germanophone, sonne comme une revanche historiographique, plusieurs décennies après la fondation de l'Institut de culture matérielle du Moyen Âge (1969), rattaché depuis à l'université de Salzbourg et étendu à la période moderne. Cette institution, ainsi que l'Institut d'histoire médiévale de Munich, fournit un grand nombre des collaborateurs d'un réseau scientifique soutenu par la Deutsche Forschungsgemeinschaft entre 2010 et 2014 et dont les travaux sont présentés dans cet ouvrage. Le recueil contient douze articles, dont deux composés à quatre mains : on regrettera à ce sujet l'absence de notices bio-bibliographiques des

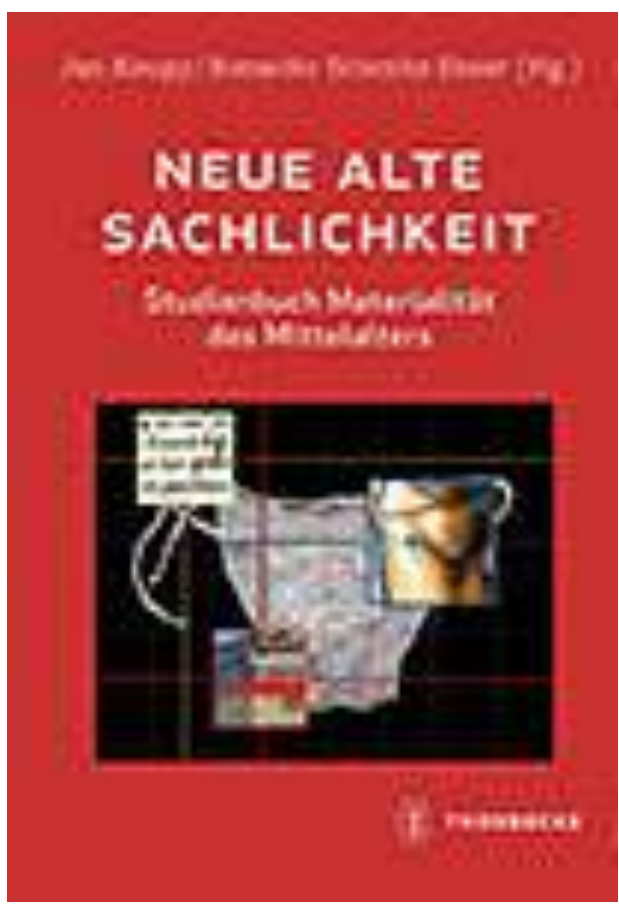
auteurs.

L'objectif de l'ouvrage est de présenter les méthodes et la richesse d'une histoire matérielle et de contribuer ainsi à une "matérialisation" de la médiévistique. Les articles sont bâtis sur un protocole commun, dont les auteurs soulignent dans une longue introduction les vertus simplificatrices et empiriques tout en reconnaissant ses limites : une histoire de l'objet, une histoire « dans » l'objet et une histoire « à partir de l'objet ", interrogeant de ce fait le contexte de découverte et de production ainsi que les différents usages et valeurs associés à ces produits médiévaux.

L'ordre des contributions n'est pas expliqué, ni par la chronologie des objets (du XII ${ }^{\mathrm{e}}$ au $\mathrm{XV}^{\mathrm{e}}$ siècle) ni par leur typologie. La plupart des objets envisagés ont été produits ou conservés dans l'espace germanophone, et notamment autrichien. Tous les articles n'apparaissent pas nécessairement comme originaux (ainsi sur l'église octogonale d'Ottmarsheim en Alsace ou le programme héraldique de Frédéric III à Wiener Neustadt). En revanche, on appréciera la variété des objets présentés et l'abondance des illustrations: étole des insignes impériaux, tablettes de plomb, enseignes de pèlerinages, bannières municipales, héraldique monumentale, architecture religieuse, peignes, sous-vêtements, gourdes, gemmes et chartriers.

Tandis que certains sont des trouvailles archéologiques récentes, d'autres sont depuis longtemps des objets patrimoniaux, mais là encore chaque objet dispose de son propre " cycle de vie ", notamment lorsque l'objet est perdu, déposé, que l'on décide de le conserver ou de s'en débarrasser. Maniables ou monumentaux, objets du quotidien ou uniques n'offrent pas les mêmes perspectives de description interne, ce qui explique une répartition souvent inégale du contenu et des illustrations. Une contribution présente à travers un objet disparu et décrit succinctement - un siège ou fauteuil d'invalide présent à l'expédition romaine de Frédéric III - les difficultés à cerner la matérialité à travers les sources écrites. Souvent sous forme d'enquête, faute d'une contextualisation univoque fournie par d'autres sources, ces contributions problématisent les interprétations divergentes que l'on peut faire d'un objet, qui se 
laisse appréhender par l'observateur, mais dont les attributions d'usage ne peuvent être garanties sans établir une histoire de l'objet et l'établissement d'un corpus d'objets similaires. En cela, l'ouvrage remplit largement sa promesse d'être un livre d'études, dont les différentes méthodes d'approche permettent d'interroger les nôtres.

Les questionnements théoriques et l'approche ludique trouvent leur traduction dans l'objet-livre : le papier glacé et l'image de couverture déroutent au premier abord, mais le lecteur apprécie progressivement les appels discrets des nombreux encadrés thématiques. Le ton truculent, plein de jeux de mots, mêlant Tolkien et Latour, contribue à l'approche pédagogique, même si certaines illustrations et schémas peuvent parfois surprendre.

INDEX

Index chronologique : Moyen Âge

Thèmes : Histoire de la culture, Histoire sociale 